Original Research Paper

\title{
Women's Participation in Agricultural Activities at Forest Land Areas of Bangladesh
}

\author{
Rajwana Munmun, Md. Asaduzzaman Sarker, \\ Mohammad Jiaul Hoque and Khondokar Humayun Kabir \\ Department of Agricultural Extension Education, \\ Bangladesh Agricultural University, Mymensingh-2202, Bangladesh
}

Article history

Received: 04-03-2015

Revised: 11-04-2015

Accepted: 30-04-2015

Corresponding Author:

Kabir, K.H.

Department of Agricultural

Extension Education, Bangladesh

Agricultural University,

Mymensingh-2202, Bangladesh

E-mail: kabirag09@bau.edu.bd

\begin{abstract}
Women first initiated agricultural practices and demonstrated the art of science of farming. Women played a key role in the conservation of basic support system. The main objective of this research was to determine the extent of participation in agricultural activities by the rural women in Madhupur forest areas. An attempt was made to explore the potentials factors that influence their participation in agricultural activities in Madhupur forest areas in Bangladesh. Data were collected from randomly selected 70 rural women by using a pre-tested structured interview schedule. The findings of the study showed that the highest proportion of the respondents $(95.7 \%)$ had high level of participation in agricultural activities, where only $4.3 \%$ had medium and $1.4 \%$ had low level of participation. Among nine selected characteristics of the rural women, two of these namely years of schooling and family farm size did not show positive significant relationships with their extent of participation in agricultural activities. On the other hand, extension media contact and access to training on agriculture showed positive significant relationship with their extent of participation in agricultural activities. The findings of the study indicate that the respondents of the study area have no alternatives other than agricultural activities. Here, more than half of respondents $(62.9 \%)$ motivated towards agricultural activities as they have no alternatives to do, where, 25.7 and $11.4 \%$ of them were self-motivated and enforced by other to practice agricultural activities, respectively. More training should be provided to the women farmers of the study areas and require more exposure to extension media which helps the people to become more conscious, rational decision maker and informative about agricultural activities. So the authority should implement adequate development program in the forest areas for the welfare of women farmers.
\end{abstract}

Keywords: Participation, Agricultural Activities, Rural Women

\section{Introduction}

\section{Background Discussion}

Agriculture is the economic backbone of Bangladesh with approximately $80 \%$ of its 170 million people depending on it for subsistence. About one-fifth of GDP $(20.01 \%)$ comes from agriculture sector (BBS, 2012). Women contribute around half of the population in Bangladesh and majority of them live rural areas (BBS, 2010). Women contribute in agricultural production but it has hardly been recognized. Because of existence of traditional society male generally dominate in development activities.

According to some historians, women first initiated agricultural practices and demonstrated the art of science of farming. Women played a key role in the conservation of basic support system such as land, water, flora and fauna (Swaminathan, 1985). Besides, in the rural areas, 
the women form about half of the rural population is particularly disadvantaged. They have been contributing significantly through their agricultural and household works. However, their efforts do not get reflected in the official statistics (Zaman, 2002). The women have to work under harsh condition defying social, religious barriers and discriminations. Women make essential contributions to the agricultural and rural economies in all developing countries. Their roles vary considerably between and within regions and are changing rapidly in many parts of the world, where economic and social forces are transforming the agricultural sector (SOFA, 2011).

Considerable amounts of literature all over the world have established that women are involved in agricultural activities alongside other domestic works (Sarma, 2009; Bhattacharyya et al., 2010; 2011; Bhattacharyya and Vauquine, 2013). Data provided by the FAO (2010) revealed that in developed countries, women's contribution to agricultural labor force was $30.7 \%$ while for developing countries it was $43.6 \%$ (Fig. 1). Female farmers are considered as efficient as men; however, they do not perform as well because they do not have access to the same inputs, services and productive resources-including water. In Bangladesh, women play a crucial role within the smallholders system and are commonly responsible for the production of food crops, especially where the farming system includes both food and cash crops. Moreover, Agriculture is underperforming in many developing countries for a number of reasons. Among these is the fact that women lack the resources and opportunities they need to make the most productive use of their time. Women are farmers, workers and entrepreneurs, but almost everywhere they face more severe constraints than men in accessing productive resources, markets and services. This "gender gap" hinders their productivity and reduces their contributions to the agriculture sector and to the achievement of broader economic and social development goals. Closing the gender gap in agriculture would produce significant gains for society by increasing agricultural productivity, reducing poverty and hunger and promoting economic growth (FAO, 2011).

However, activities performed by men are visible whereas those by women are invisible. Sectarians faced by the women in Madhupur are deep rooted in cultural values, normative patterns and customs, most of which are without religious and ethical sanction. They are never recognized for their labor. Thus, the present study was undertaken to assess their extent of participation in agricultural activities.

\section{Statement of the Problem}

In view of the above background and facts, it could be mentioned that rural women's participation in agricultural activities is a vital factor to ensure agricultural production for fulfillment of the country's demand. However, general background of the study reveals that different social barriers act as a serious hindrance against desire agricultural production. On the other hand, rural women are participating agricultural activities instead of having serious barriers. Thus, considering this fact, it is necessary to identify those crucial barriers against rural women's participation in agricultural activities for improving higher agricultural production. This may act as influential factors to increase rural women's participation in agricultural activities. Keeping this in mind our study aims to answer the following research questions:

- What was the status of existing level of participation of rural women in different agricultural activities?

- What were the important characteristics of rural women that explored relationship with their participation in agriculture activities?

- Participation of rural women in agricultural activities affected by their personal characteristics (e.g., age, education, family size, farm size, family income, personal income access to credit, access to training etc

\section{Objectives}

With the background information and research questions, this paper is devoted to explore necessary information and facts with the following objectives:

- To assess the extent of women's participation in agricultural activities

- To find out the potential factors that may affect the women's participation in agricultural activities

\section{Materials and Methods}

The study was conducted in two villages namely Jolchatra and Gachabari of Madhupur upazila under Tangail district (Fig. 1). The study areas were selected purposively because of good communication facilities and the study areas were adjacent to each other and located by the side of the Madhupur, Tangail. Moreover, there are no enough studies about the participation of the women in agricultural activities and that is why, the researcher undertook the present study.

Ex-post facto research design was employed to find out the consistency of the findings. Both qualitative such as observations and quantitative survey approach were used to investigate participation of women in agricultural activities and also to interpret survey results. 
Forest farm families of the two selected villages of Arunkhola union of Madhupur upazila were the population of the study. The total list of forest farm families of the study area was collected from the office of Upazila Agriculture Officer of Madhupur upazila under Tangail District (Fig. 2). There were 160 and 230 farm families in Jolchatra and Gachabari villages, respectively. Thus, a total of 390 farm families constituted the population of the study. It was considered that each family contained at least one housewife. Thus, 70 housewives among the 390 farm families (around $18 \%$ ) constituted the sample of the study (Table 1).

In order to collect valid and reliable data from the respondents an interview schedule was designed keeping the research objectives in mind. Simple and direct questions and also a number of scales were included in the data collecting instrument for gathering data as per objectives. Data was collected using pre-tested interview schedule and on the basis of pre-test experiences necessary corrections, modifications and alternations were made before finalizing the interview schedule for final data collection. A discussion was also made about the matter with the husbands of the respondent separately as and when required. Necessary clarifications were also given as and when required. Data were collected during 10th to 30th March, 2014.

\section{Measurement of Focus Variable}

Participation of women in agricultural activities was the focus variable of the study. It was measured by asking their responses against a 4-point rating scale viz. frequently, occasionally, rarely and not at all and weights of responses were: 3 for frequently, 2 for occasionally, 1 for rarely and 0 for not at all. The scale contained twenty five activities broadly divided into three dimensions such as crop management, forest management and livestock management.

The participation score was obtained by adding weights of responses of the activities and therefore, the participation score could vary from 0 to 75 , where 0 indicating 'no participation' and 75 indicating 'high participation'.

Table 1. Distribution of population and sample of the women in two villages of Madhupur upazila

\begin{tabular}{|c|c|c|c|c|}
\hline Union & Villages & $\begin{array}{l}\text { Total no. of } \\
\text { farm families }\end{array}$ & Sample size & Reserve list \\
\hline \multirow[t]{2}{*}{ Arunkhola } & Jolchatra & 160 & 30 & 5 \\
\hline & Gachabari & 230 & 40 & 5 \\
\hline Total & & 390 & 70 & 10 \\
\hline
\end{tabular}

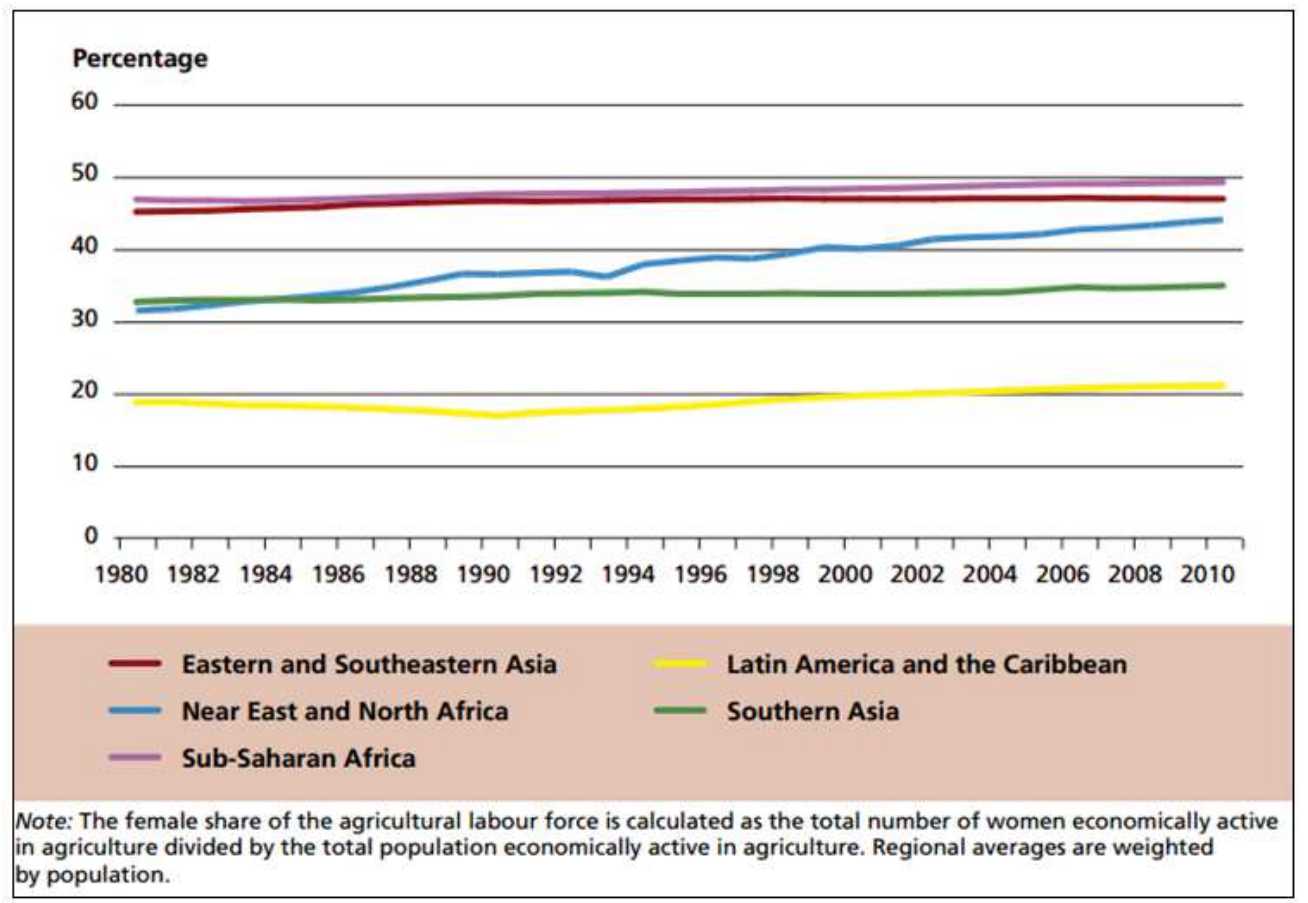

(Source: FAO, 2010)

Fig. 1. Female share of the agricultural labor force 


\section{Data Analysis}

Data collected from the respondents were verified, compiled, tabulated and analyzed statistically according to the objectives of the study. In some cases, qualitative data were converted to quantitative data by means of suitable scoring to facilitate interpretation. Data were analyzed based on the nature of the data collected. The statistical measurement used in describing the selected explanatory and focus variables were frequency distribution, range, percentage, mean and standard deviation. To clarify the understanding tables were used in presenting data.

Pearson's Product Moment Co-efficient of Correlation analyses were employed for exploring relationship between extent of participation of forest women in agricultural activities and their selected characteristics. The Statistical Package for Social Science (SPSS) computer program was used in analyzing data.

\section{Results and Discussion}

Result in Table 2 shows that majority (50.0\%) of the respondent's belonged to middle age group followed by young age $(47.1 \%)$ and old age $(2.9 \%)$ group. The frequency distribution was highly skewed towards the younger to middle aged respondents. It therefore, spells out that the young and middle aged women of the study area could have considerable extent of participation in agricultural activities.

While looking at the educational status of respondent, result revealed that the highest proportion of the respondents $(88.6 \%)$ had primary education, where $11.4 \%$ of them had secondary level of education and no women $(0 \%)$ were illiterate. This is due to the reason that many NGOs and Christian missionaries have free education programme in the study area. Education is important factor in acquiring knowledge and information about different aspects of living. So, it can be mentioned that the women of the study area could participate in agricultural activities with adequate knowledge about farming.

Out of total 70 farmers under study, $37.1 \%$ were in the large sized household, compared to $35.7 \%$ of them being medium household size and $27.2 \%$ of them in the small household size. Moreover, it was observe that the highest proportion of the respondents (37.1\%) had large farm size, where 35.7 and $27.1 \%$ of them had medium and large farm size, respectively. The results also show that the majority of the respondents $(72.86 \%)$ had less personal assets, where 21.43 and $5.71 \%$ of them had medium and high personal assets, respectively. Data presented in the Table 2 show that the highest proportion of the respondents $(63 \%)$ were in low income category, where 24.1 and $12.9 \%$ of them were in medium and high income category, respectively. The findings indicate that majority of the farmers $(87.1 \%)$ were in the low to medium income category. It was observed that the highest proportions of the respondents (74.2\%) were in medium category of extension media contact, where $25.8 \%$ of them had low extension media contact and none of them had high category of extension media contact. Contact with different extension media increases the opportunity of respondents of getting information about farming activities. Furthermore, the highest proportion of the respondents $(52.9 \%)$ had low training exposure, where 35.7 and $11.4 \%$ of them belonged to medium and no training exposure, respectively. Finally, data presented in the Table 2 show that the highest proportion of the respondents (94.3\%) had low access to credit, where 4.3 and $1.4 \%$ of them had medium and high access to credit, respectively.

\section{Motivation of the Women towards Agricultural Activities}

This section will present the findings of the motivation of women towards agricultural activities.

The data presented in the Table 3 indicate that more than half of respondents $(62.9 \%)$ motivated towards agricultural activities as they have no alternatives to do, where, 25.7 and $11.4 \%$ of them were self-motivated and enforced by other to practice agricultural activities, respectively.

\section{Participation in Agricultural Activities}

The participation scores of the respondents ranged from 25-75 against a possible range of 0-75, with an average of 60.19 and standard deviation 6.19 . On the basis of their participation scores, the respondents were classified into three categories i.e., low, medium and high. Distribution of the respondents according to their extent of practice of agricultural activities has been shown in Table 4 .

Data presented in the Table 4 show that the highest proportion of the respondents $(95.7 \%)$ had high level of participation in agricultural activities, where only 4.3 and $1.4 \%$ of them had medium and low level of participation, respectively. The findings indicate that near about cent per cent of the respondents $(95.7 \%)$ used to participate in agricultural activities. It may be due to the reason that agriculture could be the only way of livelihood of the people in the forest areas and the women do not have alternative activities other than agriculture.

Data in Table 5 indicate that participation of women is high in rice drying. In the study area out of 70 women, 48 were frequently, 16 are occasionally, 2 are rarely participating rice drying and 4 women are not at all in participating rice drying. 
Rajwana Munmun et al. / Journal of Social Sciences 2015, 11 (1): 30.38 DOI: $10.3844 /$ jssp.2015.30.38

Table 2. Characteristics profile of the respondents $(n=70)$

\begin{tabular}{|c|c|c|c|c|c|c|c|}
\hline \multirow[b]{2}{*}{$\begin{array}{l}\text { Characteristics } \\
\text { (Measuring units) }\end{array}$} & \multicolumn{2}{|c|}{ Score ranges } & \multirow[b]{2}{*}{ Categories } & \multicolumn{2}{|c|}{ Respondents } & \multirow[b]{2}{*}{ Mean } & \multirow[b]{2}{*}{ SD } \\
\hline & Possible & Observed & & ----- & \% & & \\
\hline \multirow[t]{3}{*}{ Age (Years) } & unknown & $21-51$ & Young (up to 35) & 33 & 47.1 & 36.57 & 7.75 \\
\hline & & & Middle aged (36-50) & 35 & 50.0 & & \\
\hline & & & Old (above 50) & 2 & 2.9 & & \\
\hline \multirow{3}{*}{$\begin{array}{l}\text { Years of schooling (Total } \\
\text { years of schooling) }\end{array}$} & unknown & $1-8$ & Illiterate $(0)$ & 0 & 0.0 & 2.47 & 1.94 \\
\hline & & & Primary $(1-5)$ & 62 & 88.6 & & \\
\hline & & & Secondary (6-10) & 8 & 11.4 & & \\
\hline \multirow{3}{*}{$\begin{array}{l}\text { Household size (No. of } \\
\text { members) }\end{array}$} & unknown & $2-14$ & Small (up to 4) & 19 & 27.2 & 6.40 & 2.69 \\
\hline & & & Medium (5-7) & 25 & 35.7 & & \\
\hline & & & Large (above 7) & 26 & 37.1 & & \\
\hline \multirow{3}{*}{ Family farm size (Hectare) } & unknown & $0.30-1.98$ & Small (0.02-0.99) & 19 & 27.1 & 0.89 & 0.45 \\
\hline & & & Medium (1.0-.0-3.0) & 25 & 35.7 & & \\
\hline & & & Large (above 3.0) & 26 & 37.1 & & \\
\hline \multirow[t]{3}{*}{ Personal assets (000’ Taka) } & unknown & $3.3-7.80$ & Less (up to 50) & 57 & 81.4 & 30.09 & 20.04 \\
\hline & & & Medium (50.1-100) & 13 & 18.6 & & \\
\hline & & & High (above 100) & 0 & 0.0 & & \\
\hline \multirow{3}{*}{$\begin{array}{l}\text { Personal annual income } \\
(000 \text { ' Taka) }\end{array}$} & unknown & $6-95$ & Low (up to 31) & 44 & 63.0 & 31.08 & 23.32 \\
\hline & & & Medium (32-63) & 17 & 24.1 & & \\
\hline & & & High (above 63) & 9 & 12.9 & & \\
\hline \multirow{3}{*}{$\begin{array}{l}\text { Extension media contact } \\
\text { (Scores) }\end{array}$} & $0-42$ & $6-27$ & Low (up to 14) & 18 & 25.8 & 17.93 & 4.39 \\
\hline & & & Medium (15-28) & 52 & 74.2 & & \\
\hline & & & High (above 28) & 0 & 0.0 & & \\
\hline \multirow[t]{3}{*}{ Access to training (Days) } & unknown & $1-6$ & No training $(0)$ & 8 & 11.4 & 2.81 & 1.91 \\
\hline & & & Short duration (1-3) & 37 & 52.9 & & \\
\hline & & & Medium (4-7) & 25 & 35.7 & & \\
\hline \multirow[t]{3}{*}{ Access to credit ( $000^{\prime}$ Taka) } & unknown & $0-79.40$ & Low (up to 26 ) & 66 & 94.3 & 11.22 & 12.79 \\
\hline & & & Medium (27-53) & 3 & 4.3 & & \\
\hline & & & High (above 53) & 1 & 1.4 & & \\
\hline
\end{tabular}

Table 3. Distribution of the respondents according to their attitude towards agricultural activities

\begin{tabular}{lcr}
\hline & Respondents $(\mathrm{n}=70)$ & \\
Categories & $-\mathrm{c}$ Number & Percent \\
\hline Self-motivated & 18 & 25.7 \\
Enforced by other & 8 & 11.4 \\
No alternatives & 44 & 62.9 \\
Total & 70 & 100.0 \\
\hline
\end{tabular}

Table 4. Distribution of the respondents according to their extent of participation in agricultural activities

\begin{tabular}{|c|c|c|c|c|c|c|}
\hline \multicolumn{2}{|c|}{ Score range } & \multirow[b]{2}{*}{ Categories } & \multicolumn{2}{|c|}{ Respondents $(\mathrm{n}=70)$} & \multirow[b]{2}{*}{ Mean } & \multirow[b]{2}{*}{ SD } \\
\hline Possible & Observed & & Number & Percent & & \\
\hline \multirow[t]{4}{*}{$0-75$} & $25-75$ & Low (up to 25) & 1 & 1.4 & 60.19 & 6.19 \\
\hline & & Medium (26-50) & 3 & 4.3 & & \\
\hline & & High (above 50) & 66 & 95.7 & & \\
\hline & & Total & 70 & 100.0 & & \\
\hline
\end{tabular}

The second highest participation is in threshing. In the study area out of 70 women, 61 are frequently, 8 are occasionally, 1 are rarely participating in threshing.
The third one is drying and storing. In the study area out of 70 women, 63 are frequently, 3 are occasionally, 3 are rarely participating in drying and storing and 1 women are not at all participating in drying and storing. 


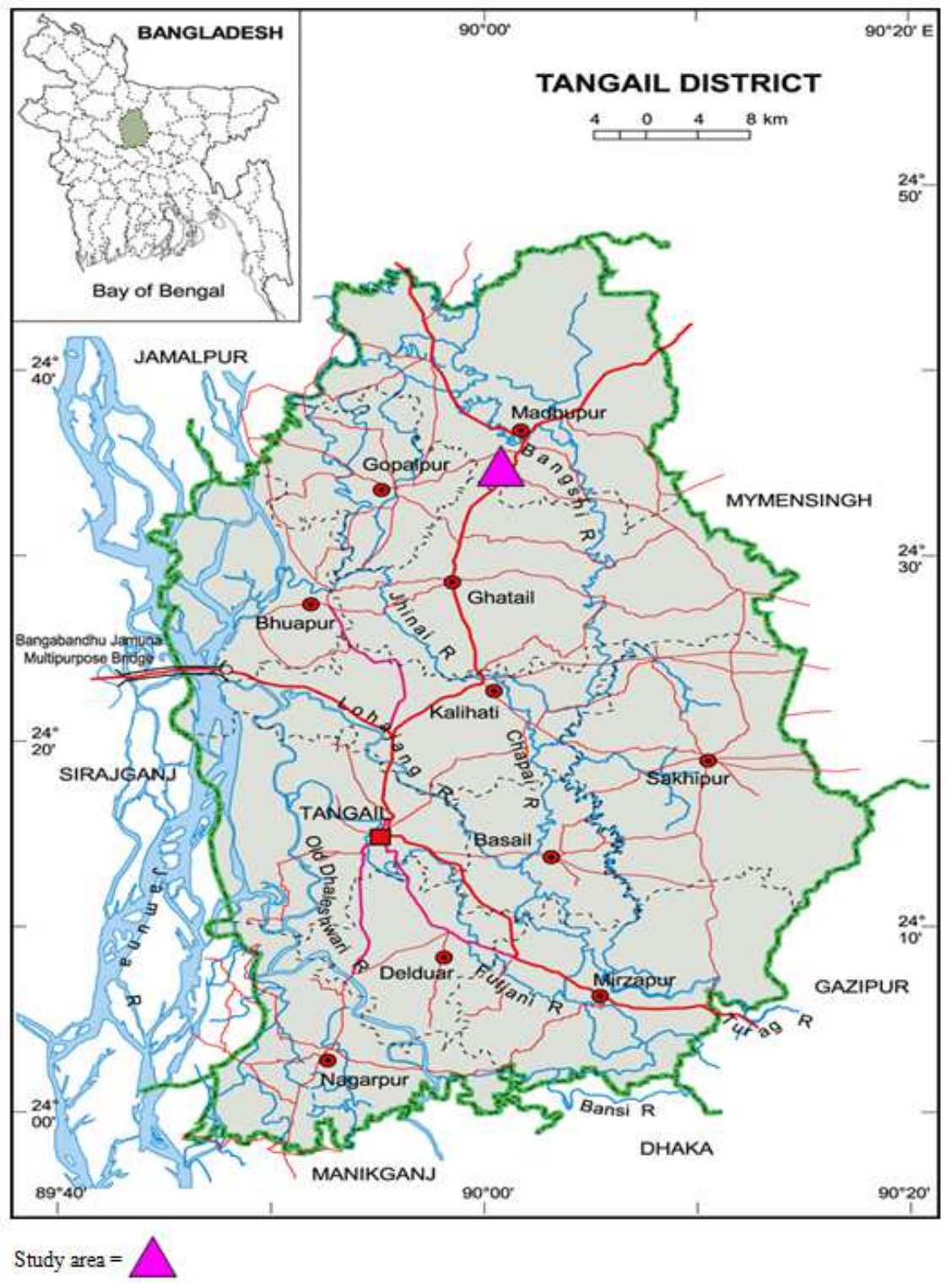

Fig. 2. A map of Tangail District showing MadhupurUpazila

The forth one is rice boiling. In the study area out of 70 women, 54 are frequently, 12 are occasionally and 4 are rarely participating in rice boiling. Then extent of participation of women are Nursery raising and seed sowing, Cattle and goat management, Weeding, Harvesting, Cleaning of cattle and poultry shed, Poultry keeping, Uprooting of seedlings and transplanting, Straw drying, Collection of dead branches, Collection of leaf debris, Training of plants, Marketing, Feeding, Irrigating crop fields, Pruning of plants, Seed treatment, Rice husking, Germination testing, Milking, Land preparation/ploughing and Pesticide spraying, respectively.
Relationship between Selected Characteristics of Women and their Participation in Agricultural Activities

This section deals with the findings exploring the relationships between the explanatory and focus variables of the study. The explanatory variables were age, year of schooling, household size, farm size, personal annual income, extension media contact, access to training and access to credit. The focus variable was "Participation of Women in Agriculture Activities". The results of correlation of co-efficient test between the explanatory and focus variables have been shown in Table 6 . 
Table 5. Rank order of participation of women in agricultural activities

\begin{tabular}{|c|c|c|c|c|c|c|}
\hline \multirow[b]{2}{*}{ Topics } & \multicolumn{4}{|c|}{ Extent of participation $(\mathrm{N}=70)$} & \multirow[b]{2}{*}{ PI } & \multirow[b]{2}{*}{ Rank order } \\
\hline & Frequently & Occasionally & Rarely & Not at all & & \\
\hline \multicolumn{7}{|l|}{ Crop management } \\
\hline Seed treatment & 5 & 3 & 40 & 22 & 61 & 20 \\
\hline Germination testing & 4 & 5 & 20 & 41 & 42 & 22 \\
\hline Nursery raising and seed sowing & 55 & 10 & 3 & 2 & 188 & 5 \\
\hline Land preparation/ploughing & 0 & 2 & 7 & 61 & 11 & 24 \\
\hline Uprooting of seedlings and transplanting & 33 & 23 & 2 & 12 & 147 & 11 \\
\hline Weeding & 38 & 22 & 8 & 2 & 166 & 7 \\
\hline Irrigating crop fields & 6 & 12 & 32 & 20 & 74 & 18 \\
\hline Pesticide spraying & 0 & 0 & 3 & 67 & 3 & 25 \\
\hline Harvesting & 45 & 12 & 3 & 0 & 162 & 8 \\
\hline Threshing & 61 & 8 & 1 & 0 & 200 & 2 \\
\hline Drying and storing & 63 & 3 & 3 & 1 & 198 & 3 \\
\hline Rice Boiling & 54 & 12 & 4 & 0 & 190 & 4 \\
\hline Rice drying & 48 & 16 & 2 & 4 & 226 & 1 \\
\hline Rice husking & 6 & 14 & 14 & 36 & 60 & 21 \\
\hline Straw drying & 10 & 51 & 6 & 3 & 138 & 12 \\
\hline \multicolumn{7}{|l|}{ Forest management } \\
\hline Collection of leaf debris & 13 & 27 & 20 & 10 & 113 & 14 \\
\hline Training of plants & 18 & 12 & 15 & 25 & 93 & 15 \\
\hline Pruning of plants & 9 & 11 & 13 & 37 & 62 & 19 \\
\hline Collection of dead branches & 17 & 30 & 12 & 11 & 123 & 13 \\
\hline \multicolumn{7}{|l|}{ Livestock activities } \\
\hline Cattle and goat management & 45 & 15 & 8 & 2 & 173 & 6 \\
\hline Poultry keeping & 39 & 11 & 12 & 8 & 151 & 10 \\
\hline Cleaning of cattle and poultry shed & 31 & 24 & 13 & 2 & 154 & 9 \\
\hline Feeding & 17 & 21 & 26 & 6 & 81 & 17 \\
\hline Milking & 4 & 6 & 5 & 55 & 29 & 23 \\
\hline Marketing & 7 & 14 & 36 & 13 & 85 & 16 \\
\hline
\end{tabular}

Table 6 . Correlation between explanatory and focus variables $(n=70)$

\begin{tabular}{|c|c|c|c|c|}
\hline \multirow[b]{2}{*}{ Focus variable } & \multirow[b]{2}{*}{ Explanatory variables } & \multirow{2}{*}{$\begin{array}{l}\text { Correlation co-efficient } \\
\text { (r) values with } 68 \mathrm{df}\end{array}$} & \multicolumn{2}{|c|}{ Tabulated $\mathrm{r}$ values with $68 \mathrm{df}$} \\
\hline & & & 0.05 level & 0.01 level \\
\hline Participation of Women in & Age & 0.141 & 0.235 & 0.306 \\
\hline \multirow{8}{*}{ Agricultural Activities } & Years of schooling & $-0.366^{* *}$ & & \\
\hline & Family size & -0.033 & & \\
\hline & Family farm size & $-0.307^{* *}$ & & \\
\hline & Personal annual income & -0.117 & & \\
\hline & Personal assets & 0.083 & & \\
\hline & Extension media contact & $0.301^{*}$ & & \\
\hline & Access to training on agriculture & $0.429^{* *}$ & & \\
\hline & Access to credit & 0.110 & & \\
\hline
\end{tabular}

Pearson's Product Moment Co-efficient of Correlation (r) was used to test the null hypothesis concerning the relationships between two variables. Five percent (0.05) level of probability was used as the basis for rejecting the null hypothesis.

A significant but negative relationship was found between year of schooling and their participation in agricultural activities. This may be due to the women having more years of schooling showed the tendency of avoiding labor and hence, their participation in agricultural activities had low. Khan (2004; Khatun, 2004; Islam, 2003; Azad, 2003) found similar findings. This is due to the reason that women having more education feel dishonor to participate in agricultural activities.

Family farm size showed a negative significant relationship with the participation of women in agricultural activities. Based on the findings, it was therefore concluded that the respondents having larger farm size had low participation in agricultural activities. Farm size is an important indicator for socio-economic status of the farm women. The finding may be due to that the family having large farm size could perform agricultural activities by hiring labor and not to employ 
their family women in agricultural activities. Islam (2003; Amin, 2004; Khan, 2004) also found similar findings in their studies.

A significant and positive relationship was found between extension media contact and the participation of women in agricultural activities. It was therefore concluded that the women having higher contact with extension media had higher participation in agricultural activities. This may be due to the fact that the extension personnel can provide adequate information about different aspects of agriculture and also can motivate the women to do so. Amin (2004) also observed similar findings in their studies.

Finally, a significant and positive relationship was found between accesses to training and the participation of women in agricultural activities. This finding leads us to conclude that the women having higher training exposure had higher participation in agricultural activities. Training broadens the outlook of the respondents and also provides skills to perform the activities effectively. So, it can be mentioned that after attaining training activities the women could learn about different aspects of agriculture and hence, the finding indicate higher participation in agricultural activities of the women.

\section{Conclusion and Recommendation}

Based on the results obtained it can be concluded that $62.9 \%$ women of the study area was motivated towards agricultural activities, when they have no alternatives and $25.7 \%$ of the women showed selfmotivation to practice different agricultural activities. Moreover, findings indicate that near about $95.7 \%$ of the respondents in the study areas participate in agricultural activities. The findings lead to the conclusion that agriculture might be the main occupation of the farm families to lead their livelihood and hence, majority of the women participated in agricultural activities. The women farmers play a vital role to get more earnings from agricultural activities that would make improved socio-economic conditions of the farm families.

Further analysis using Pearson product moment correlation has detected that extension media contact and access to training program have a positive and significant relationship with women participation in agricultural activities. However, there was a negative and significant relationship with year of schooling and family farm size of the respondents and their agricultural activities.

The study recommends that as the respondents of the study area have no alternatives other than agricultural activities, so, different development agencies including GOs and NGOs should provide necessary inceptives and support to them for their increased crop production in a sustainable means. More training should be provided to the women farmers of the study areas so that they can do their farming activities more efficiently.

Extension media contact helps the people to become more conscious, rational decision maker and informative about agricultural activities. The extension personnel should provide regular visit to the women so that they can make effective communication with them for their farming activities. It is strongly recommended that the authority should provide adequate development program in the forest areas for the welfare of women farmers.

\section{Acknowledgement}

The researchers are thankful to the women who gave information and cooperate nicely.

\section{Author's Contributions}

Rajwana Munmun: Questionnaire preparation, data collection and data insert and preparation of raw manuscript.

Md. Asaduzzaman Sarker: Supervise questionnaire preparation and data collection, Data analysis, preparations of tables and editing the manuscript.

Mohammad Jiaul Hoque: Supervise questionnaire preparation and data collection, Data analysis, preparations of tables and editing the manuscript.

Khondokar Humayun Kabir: Final manuscript preparation, setting tables and graphs and maintaining correspondence with editor.

\section{Ethics}

This article is original and contains unpublished material. The corresponding author confirms that all of the other authors have read and approved the manuscript and no ethical issues involved.

\section{References}

Amin, M.R., 2004. Participation of rural women in selected aquaculture activities. MSc Thesis, Bangladesh Agricultural University.

Azad, M.A.K., 2003. Participation of women in decision making regarding farming activities in two selected in two selected villages of Patuakhali, District. MSc Thesis, Bangladesh Agricultural University.

BBS, 2010. Statistical year book of Bangladesh. Bangladesh Bureau of Statistics Statistics Division, Ministry of Planning, Government of the People's Republic of Bangladesh, Dhaka. 
BBS, 2012. Statistical year book of Bangladesh. Bangladesh Bureau of Statistics Statistics Division, Ministry of Planning, Government of the People's Republic of Bangladesh, Dhaka.

Bhattacharyya, R. and P. Vauquline, 2013. A mirage or a rural life line? Analysing the impact of mahatma Gandhi rural employment guarantee act on women beneficiaries of Assam. Space Culture Ind., 1: 83-101.

Bhattacharyya, R., P. Vauquline and S. Singh, 2010. Towards a socially sustainable India: An analysis of national rural employment guarantee scheme, 2006. Proceedings of the Strategic Management of Energy, Environment and Disaster for Sustainable, (EDS' 10), USA in Collaboration with Banaras Hindu University, Varanasi, India, pp: 62-74.

Bhattacharyya, R., P. Vauquline and S. Singh, 2011. Towards a Socially Sustainable India: An Analysis of National Rural Employment Guarantee Scheme, 2006. In: Energy Resources, Alternative Search and Sustainable Development, Singh, S.K., R. Kumar, H.P. Mathur, N.B. Singh and V.K. Kumra (Eds.), Shree Publishers, New Delhi, ISBN: 978-81-8329-395-2, pp: 73-88.

FAO, 2011. Women in agriculture: Closing the gender gap for development. FAO.

FAO, 2010. FAOSTAT statistical database. FAO.
Islam, M.Z., 2003. Participation of rural women in goat rearing in selected area under Mankikgonj district. MSc Thesis, Bangladesh Agricultural University.

Khan, M.A.S., 2004. Farmers' participation in farm and community level activities in SailokupaUpazila under Jhenaidah district. MSc Thesis, Bangladesh Agricultural University.

Khatun, F., 2004. Participation of rural women in homestead management activities. MSc Thesis, Bangladesh Agricultural University.

Sarma, R.B., 2009. Feminist Political Economy. In: International Encyclopedia of Human Geography, Kitchin, R. and N. Thrift (Eds.), Elsevier, Oxford, ISBN-10: 978-0-08044911-1, pp: 79-86.

SOFA, 2011. The role of women in agriculture. ESA working paper no. 11-02. Agricultural Development Economics Division, FAO.

Swaminathan, M.S., 1985. Imparting rural women users perspective to agricultural research and impacting-a draft paper for discussion. Proceedings of the Workshop in Rice Farming System, Apr. 10-13, Philippines, Los Banos.

Zaman, S.U., 2002. Women's role and status in Bangladesh agriculture. Association of Development Agencies in Bangladesh (ADAB), Dhaka, Bangladesh. 